Similitudes y diferencias en la historiografia del deporte en Brasil y Francia: un diálogo con "Histoire du sport" de Thierry Terret Marcelo Moraes e Silva - Daniele Cristina Carqueijeiro de Medeiros Evelise Amgarten Quitzau - Alejo Levoratti Anuario No 33 / ISSN 1853-8835 / 2020 http://anuariodehistoria.unr.edu.ar/ojs/index.php/Anuario/index

\title{
Similitudes y diferencias en la historiografia del deporte en Brasil y Francia: un diálogo con "Histoire du sport" de Thierry Terret
}

\author{
Similarities and differences in the history of sports in \\ Brazil and France: a dialogue with "Histoire du sport" \\ by Thierry Terret
}

\author{
MARCELO MORAES E SILVA \\ Universidade Federal do Paraná (Brasil) \\ marcelomoraes@ufpr.br \\ DANIELE CRISTINA CARQUEIJEIRO DE MEDEIROS \\ Universidade Estadual de Campinas (Brasil) \\ danieli_ccm@hotmail.com \\ EVELISE AMGARTEN QUITZAU \\ Universidad de la República (Uruguay) \\ eveliseaq@yahoo.com.br
}

\begin{abstract}
ALEJO LEVORATTI
Consejo Nacional de Investigaciones Científicas y Técnicas; Universidad Nacional de La Plata (Argentina)

levoratti@gmail.com
\end{abstract}

RESUMEN

El objetivo del presente artículo es evidenciar las similitudes y diferencias entre la historiografia del deporte en Francia y Brasil, tomando como base el libro "Histoire du sport", del historiador del deporte francés Thierry Terret. La obra realiza un análisis de la historiografia del deporte francesa, posibilitando un diálogo relacional entre el contexto brasileño y el francés. Como conclusión, el artículo indica que, a pesar de muchas proximidades entre las dos realidades, existen algunos distanciamientos entre los dos contextos, principalmente por las lógicas propias que el deporte tomó en cada una de estas naciones.

Palabras clave: Historia del Deporte; Historiografia; Brasil; Francia

ABSTRACT

Esta obra está sujeta a la Licencia Reconocimiento-NoComercial-Compartirlgual 4.0 Internacional de Creative Commons. http://creativecommons.org/licenses/by-nc-sa/4.0/ 


\section{Similitudes y diferencias en la historiografia del deporte en Brasil y Francia: un diálogo con "Histoire du sport" de Thierry Terret}

This paper evidences the similarities and differences between French and Brazilian historiography of sports, based on the book "Histoire $d u$ sport", written by French sports historian Thierry Terret. This book analyzes French sports historiography, allowing a comparison with the Brazilian context. In conclusion, the article points out that, although there are many proximities between both realities, there is also some distance between both contexts, mainly due to the specific logics that each nation acquired.

Keywords: Sports History; Historiography; Brazil; France

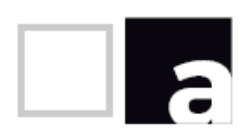

\section{Introducción}

La historia del deporte contada desde un país o una región es siempre direccionada por los principios de la universalidad y la singularidad. Esto significa que, al mismo tiempo en que el deporte se desenvolvió a partir de particularidades locales, guarda semejanzas con los eventos ocurridos en otros lugares del planeta, principalmente los surgidos en Europa. A partir de esa comprensión, innumerables estudios desplegaron las infinitas particularidades y representaciones deportivas alrededor del planeta, sus transformaciones, nuevas afiliaciones y diferentes definiciones con respecto a este objeto. Es posible afirmar, según Loudcher (2020), que las apropiaciones del fenómeno deportivo en distintos países guardan similitudes, más allá de sus particularidades.

El estudio de esas semejanzas puede ayudar en la comprensión del deporte en una escala relacional, estableciendo, a partir de ese entrecruce, semejanzas y diferencias entre los procesos. Siendo así, este artículo tiene como objetivo mostrar las similitudes y diferencias entre la historiografia del deporte en Brasil y en Francia. Para eso, fue seleccionado para la interlocución el libro "Histoire du sport", de Thierry Terret (2019), lanzado originalmente en 2007, pero se utilizó su versión revisada fechada en 2019.

El libro forma parte de la colección "Que sais-je?”, que en castellano significa “¿Qué se yo?". Se trata de un gran proyecto editorial capitaneado por Presses Universitaires de France. Esa colección es semejante a otros proyectos editoriales existentes en el escenario internacional, como los 128 de la editorial Armand Colin en Francia, las Very Short Introductions de Oxford University Press en Inglaterra, la $\mathrm{CH}$ Beck Wissen,

\section{anuario.}




\section{MARCELO MORAES E SILVA - DANIELE CRISTINA CARQUEIJEIRO DE MEDEIROS - EVELISE AMGARTEN QUITZAU - ALEJO LEVORATTI}

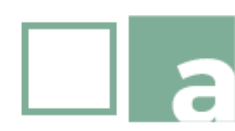

publicada por la alemana Verlag $\mathrm{CH}$ Beck y la brasileña Primeiros Passos de la Editora Brasiliense.

Thierry Terret es uno de los principales historiadores del deporte en Francia en la actualidad e investiga principalmente cuestiones relativas a deportes, género, cuerpo, educación física y movimiento olímpico. Entre los años 2001 y 2009 fue presidente de la International Society for the History of Physical Education and Sport, dirigio también la l'Association Francophone pour la Recherche sur les Activités Physiques et Sportives y la Société Française d'Histoire du Sport y desde abril de 2018 ocupa el cargo de Delegado Ministerial para los Juegos Olímpicos y Paralimpicos de Paris 2024. Terret es autor de diversas publicaciones en las principales revistas de ciencias del deporte y organizador, autor y coautor de decenas de obras, siendo reconocido como uno de los principales líderes en la historia del deporte en el escenario internacional.

Dada la importancia del autor y la relevancia de la obra en el estudio de la historia del deporte, se cree que una interlocución con el contexto brasileño puede ser de gran valor, visto que el libro no posee una versión en portugués y/o en castellano y las reflexiones en él contenidas pueden contribuir significativamente para el debate de la Historia del Deporte en Brasil y en los demás países de América del Sur. Para desarrollar el análisis aquí pretendido se dividió el artículo en cuatro partes, en las cuales se realizan diálogos entre la historia del deporte francesa y brasileña. El intento es presentar las reflexiones realizadas por Thierry Terret para trazar algunas relaciones con el contexto brasileño, evidenciando las proximidades $\mathrm{y} / \mathrm{o}$ distanciamientos entre los dos escenarios.

\section{Modelos explicativos en la historia del deporte: apropiaciones en Francia y en el Brasil}

Se inician las discusiones sobre la obra de Terret evocando las definiciones y delimitaciones trazadas por el autor en torno a la palabra deporte, fenómeno que surgió en el final del siglo XVII, en Inglaterra, en el contexto de la revolución industrial y de un capitalismo emergente que, durante el siglo XIX, se fue difundiendo por todo el mundo. Algunas filiaciones y descendencias del fenómeno deportivo son exploradas, indicando que en el final del siglo XIX el deporte comenzó a designar prácticas competitivas más codificadas e institucionalizadas en torno de los clubes, asociaciones y federaciones nacionales e internacionales. Al asumir ese posicionamiento, el autor concuerda con la vertiente teórica que hace la crítica a la existencia de una continuidad entre las prácticas de la antigüedad greco-romana con el deporte moderno, afirmando que los fenómenos presentan lógicas bastante

\section{anuario.}




\section{Similitudes y diferencias en la historiografia del deporte en Brasil y Francia: un diálogo con "Histoire du sport" de Thierry Terret}

distintas. Esta vertiente teórica es suplantada por estudios como los de Guttmann (1978; 2002), quien analiza la discontinuidad de los Juegos Olimpicos modernos y la antigüedad greco-romana, y los de Holt (1989), quien estudia el deporte inglés como un fenómeno moderno. Entre esas diferencias, se puede citar la relación tiempo y espacio y las nuevas relaciones sociales, que distancian deporte y religión $\mathrm{y}$, de esta forma, pasan a atribuirle nuevos significados.

Terret recupera los puntos que terminaron cambiando las significaciones en torno del término deporte. Para alcanzar tal propósito, el autor evoca las figuras de Pierre de Coubertin e Georges Hébert, afirmando que mientras el primero valoraba la dimensión deportiva, el segundo la cuestionaba ferozmente. Indaga cómo en torno de esas dos figuras se estableció un conflictivo debate en el escenario francés acerca de las posibilidades educativas del fenómeno deportivo. En consecuencia, afirma que la cuestión de la definición del deporte siguió como un problema importante en Francia, siendo abordado, a partir de los años 1960, por reflexiones más teóricas y militantes, con importantes contribuciones de Michel Bouet en la psicologia, de Jacques Ulmann en la historia, de Georges Magnane en la sociología y Bernard Jeu en la filosofia.

Sin embargo, una crítica más intensa al deporte fue realizada por Jean-Marie Brohm (1975; 1976), quien lo entendía como parte del sistema capitalista. En la secuencia, otros autores que ampliaron los sentidos atribuidos a la palabra "deporte" son presentados por Terret, como Pierre Parlebas, quien afirma que el deporte es un conjunto de situaciones motrices institucionalizadas y codificadas bajo la forma de competición; Donal Guay que define el deporte como una actividad física competitiva y divertida, práctica en vista de un desafio según las reglas escritas y un espíritu particular, el espíritu deportivo, repleto de equidad, deseo de vencer y lealtad; y Allen Guttmann con sus siete criterios que caracterizan al deporte moderno: a) secularización; b) igualdad; c) especialización de roles; d) racionalización; e) burocracia; f) cuantificación y g) búsqueda del record. Terret afirma que las definiciones usadas por estos autores produjeron dos grandes niveles conceptuales en Francia, uno que valorizaba más el deporte profesional y competitivo ligado a las prácticas más codificadas e institucionalizadas y otro que exaltaba la dimensión lúdica y aspectos ligados a todo tipo de ejercicio fisico con objetivos recreativos, higiénicos o competitivos, pero con un cuadro regulatorio mínimo.

Escenario similar se puede encontrar en Brasil a partir de los años 1970, cuando se establece en el país un debate entre dogmáticos y pragmáticos (Navarro, 2020; Taborda de Oliveira, 2002), que se intensifica en la década siguiente, cuando la Educación Física brasileña paso por un proceso de crisis de identidad (Quitzau y Moraes e Silva, 2020). A partir de ese momento, como señalan Torri y Vaz (2006), Souza, Oliveira y Marchi Júnior (2018), Navarro (2020) y Quitzau y Moraes e Silva (2020) una fuerte aproximación a una Teoría Critica del Deporte comenzaba a dar sus primeros pasos en el Brasil. 


\section{MARCELO MORAES E SILVA - DANIELE CRISTINA CARQUEIJEIRO DE MEDEIROS - EVELISE AMGARTEN QUITZAU - ALEJO LEVORATTI}

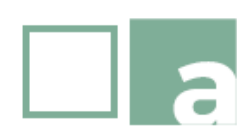

Terret también comenta los tres principales modelos de interpretación sobre la génesis del deporte moderno. La primera forma interpretativa comprendia el deporte como consecuencia de la estructura económica. Este modelo teórico es defendido por autores como el francés Jean-Marie Brohm, con fuerte impronta marxista. Tal marco establece que el deporte es un reproductor ideológico de las lógicas del sistema de producción capitalista. Terret señala que los trabajos de Brohm fundamentaron una crítica más contundente al sistema deportivo en el escenario francés, pues influenciado por eventos como el mayo de 1968, Jean-Marie Brohm pasa a mirar el fenómeno deportivo a partir de una perspectiva freudo-marxista. Otros autores franceses, como Vivier, Loudcher y Vieille-Marchiset (2005), Vivier y Loudcher (2015), Attali y Robène (2015) y Duret (2019) también indican que el sistema deportivo fue descripto por Brohm como algo estructurado dentro de una lógica capitalista, y, por ello, sería algo alienante que impedía la emancipación de los individuos.

Duret (2019), analizando la obra de Brohm, destaca que el autor inaugura una crítica radical al deporte, atribuyendo tres funciones al espectáculo deportivo. La primera sería la de garantizar que los derechos humanos no sean cumplidos por los gobiernos autoritarios. La segunda función señalada por Brohm es la relacionada a su utilización como diversión mediante conflictos políticos, comprendiendo al deporte como una versión moderna del "pan y circo" que contribuiría para un proceso de despolitización y alienación de las masas, transformándolo en una especie de "opio del pueblo". Finalmente, la tercera función del deporte sería la de convocatoria, pues los espectáculos deportivos organizan sistemáticamente una forma de identificación de campeones con sus naciones. Brohm indica que, en su mayoría, los grandes atletas presentan un posicionamiento político de derecha, casi siempre vinculados con los valores morales de la sociedad capitalista. En este sentido, según argumenta este intelectual francés, el deporte sería un poderoso vehículo de difusión de una ideología política de derecha.

El segundo tipo de abordaje se dio en torno de la sociología configuracional del alemán Norbert Elias. Según Loudcher (2020), el autor alemán ofrece una interpretación occidental basada en la observación de una represión de la violencia y de la construcción de un pudor desde la Edad Media. Este conjunto de procedimientos complejos contribuye para la formación de una civilización de las costumbres. Una serie de procesos para controlar comportamientos fueron proyectados y colocados en funcionamiento, asociando funciones biológicas -como defecar, alimentarse, beber, procrear, e incluso la violencia- a una función social a través de mecanismos de culpabilización, así como sentimientos de ansiedad y vergüenza. El resultado fue una diferenciación de las funciones sociales y el surgimiento de nuevas restricciones psíquicas que, a través de la internalización de las emociones, permitieron mayor control de las actitudes, principalmente en espacios públicos. Estos comportamientos pasan a ser rechazados, como indica

\section{anuario.}




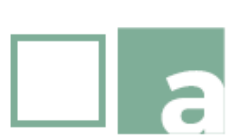

\section{Similitudes y diferencias en la historiografia del deporte en Brasil y Francia: un diálogo con "Histoire du sport" de Thierry Terret}

Dunning (1999), configurando un umbral de repugnancia. Este esquema es fundamental para entender el modelo teórico de Norbert Elias, pues este autor ubica el deporte como un elemento original del proceso de civilización. Loudcher (2020) argumenta que el sociólogo alemán proponía una homología entre esta formación bipartita presente en las elites políticas y la estructura básica de los pasatiempos que llevarian al deporte moderno. Este fenómeno fue denominado por el autor como deportivización.

A su vez, la tercera manera de interpretar el fenómeno deportivo fue formulada por Allen Guttmann. Basado en la sociología del alemán Max Weber, el intelectual norteamericano afirmaba que el deporte moderno se desenvolvió siguiendo un modelo de racionalización bastante específico, donde los medios son seleccionados en función de su eficiencia. Esa noción de utilidad apuntada por Guttmann estaba particularmente relacionada a una ética protestante y puritana dominante en la Inglaterra del siglo XVIII y que fue primordial para el advenimiento del capitalismo. En ese sentido, el autor norteamericano apunta que el proceso de desencantamiento del mundo representado por la moral protestante exigía la racionalización de elementos de la vida cotidiana y el deporte representaba ese control sobre el cuerpo y los divertimentos.

Se destaca que los tres modelos de interpretación se mostraban evidentes en Brasil. Las contribuciones de Brohm, según lo apuntado por Torri y Vaz (2006), Souza, Oliveira y Marchi Júnior (2018), Navarro (2020) y Quitzau y Moraes e Silva (2020), estuvieron bastante presentes en el país a partir de los años 1980. Los autores indican que los análisis del intelectual francés fueron muy utilizados por Cavalcanti (1984), en un libro que se tornó importante en el país, titulado "Esporte para todos: um discurso ideológico". En esta obra, la autora presenta las principales tesis del sociólogo francés, indicando las afinidades ideológicas que el deporte tenía con el capitalismo. Torri y Vaz (2006), apuntan los siguientes elementos sobre la repercusión de la obra del sociólogo francés en las reflexiones de Cavalcanti:

Apoyada en los análisis de Brohm, la autora pone en cuestión algunos de los objetivos y finalidades del programa [Esporte para todos], que hacian creer que el deporte era la actividad ideal para ocupar el tiempo de no-trabajo y para ayudar a alcanzar el equilibrio psicofisiológico. Destaca que él, al atender grandes camadas de la población, contribuía, sin embargo, para los intereses de las clases dominantes a la medida que, por ejemplo, mantenía a los dominados activos en su tiempo disponible, siendo, por tanto, una forma de control social que ayudaba en la despolitización de las masas. También con Brohm, el programa alentaba para la ampliación del mercado deportivo y la propagación de una idea especifica de cuerpo y de salud, expresión de fuerza de la técnica sobre el individuo, cosificando el cuerpo y adaptándolo a las exigencias de la tecnología (p.188 - traducción libre)

Torri y Vaz (2006), Souza, Oliveira y Marchi Júnior (2018), Navarro (2020) y Quitzau y Moraes e Silva (2020) apuntan que la obra del teórico francés fue de fundamental

\section{anuario.}




\section{MARCELO MORAES E SILVA - DANIELE CRISTINA CARQUEIJEIRO DE MEDEIROS - EVELISE AMGARTEN QUITZAU - ALEJO LEVORATTI}

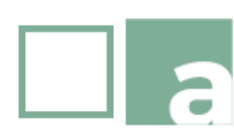

importancia para el desenvolvimiento de un discurso crítico con relación al deporte en Brasil. La búsqueda de referenciales críticos como los de Brohm estaba en sintonía con el período por el cual pasaba el país, visto que, en el final de la década de 1970, incentivada por el debilitamiento de la dictadura militar (1964-1985) y el inicio del proceso de redemocratización, surgió en el área una exploración de aportes teóricos amparados en las ciencias humanas, creando lo que se acordó en llamar como "crisis de la Educación Física".

El segundo modelo de interpretación presentado por Terret fue el más difundido en Brasil y tuvo, conforme Loudcher (2020), gran repercusión en el contexto francés, influenciando importantes intelectuales como el sociólogo Pierre Bourdieu y sus discípulos Jacques Defrance y Christian Pociello, además de historiadores como Roger Chartier y Georges Vigarello, que también hicieron uso de aportes elisianos en sus investigaciones (Pociello, 1981; Chartier y Vigarello, 1982; Bourdieu, 1987. Defrance, 2012). Souza y Marchi Júnior (2010; 2011), Reis (2014), Watson y Gastaldo (2019) destacan que la aproximación a la obra de Norbert Elias se realizó a fines del siglo XX en Brasil. Los autores indican que los estudios sociohistóricos del deporte tuvieron un gran fomento principalmente por el esfuerzo teórico de Ademir Gebara, Maria Beatriz Rocha Ferreira y Heloísa Helena Baldy dos Reis, y la aproximación personal que los investigadores brasileños tuvieran con el británico Eric Dunning, inclusive trayéndolo diversas veces a Brasil. Además, debido a sus inserciones como docentes en el Programa de Posgrado en Educación Física de la Universidad Estadual de Campinas (UNICAMP), estos investigadores formaron una serie de magísteres y doctores que difundieron el marco teórico de sociólogos como Norbert Elias, Eric Dunning e Pierre Bourdieu en el área de Educación Física en Brasil.

Souza y Marchi Júnior (2010) argumentan que varias obras sociohistóricas fueron producidas y socializadas en la esfera académica y posibilitaron un amplio proceso de recepción y apropiación de la teoría sociológica de Norbert Elias, que también permeó la historiografia del deporte en Brasil, conforme evidencian los trabajos de Medeiros y Godoy (2009), Dias (2010), Góis Júnior, Lovisolo y Nista-Piccolo (2013), Reis (2014), Souza, Starepravo y Marchi Júnior (2014) y Watson y Gastaldo (2019).

El tercer modelo de análisis también estuvo presente en Brasil, pero no con la misma fuerza y contundencia de los otros dos. La obra de Allen Guttmann a pesar de ser reconocida principalmente por su mención en el libro de Bracht (1997), prácticamente no se desarrolló. Su utilización fue bastante puntual y restrictiva. Algunos trabajos oriundos de la tradición sociohistórica formada por Ademir Gebara se aproximaron a las definiciones del teórico norteamericano, sin embargo, las producciones están más cerca de la esfera sociológica que de la histórica. Es importante destacar, como justificación de la poca utilización de su abordaje teórico en el Brasil, la inexistencia de sus trabajos en lengua portuguesa y/o castellana. La

\section{anuario.}




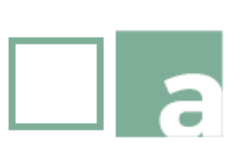

\section{Similitudes y diferencias en la historiografia del deporte en Brasil y Francia: un diálogo con "Histoire du sport" de Thierry Terret}

mayoría de sus obras solo puede ser consultadas en inglés; en portugués, existe solamente un artículo publicado en 2004 en la Revista Movimento (Guttmann, 2004) y en castellano un capítulo del libro publicado en la Argentina en 2019 (Guttmann, 2019).

El mismo escenario, según Loudcher (2008), también se dio en Francia, visto que la principal obra del autor, "From ritual to record: the nature of modern sports", publicada originalmente en 1978, fue traducida al francés solamente en 2006 (Guttmann, 2006). Terret inclusive fue el responsable del prefacio de la edición francesa del libro de Guttmann y afirma que los análisis del autor norteamericano no tuvieron tanto impacto en Francia, pues, en la década de 1980, la historia del deporte en ese país se estaba desarrollando relativamente al margen de la comunidad internacional. En ese sentido, se puede afirmar que el escenario brasileño y sudamericano es semejante al francés con relación a las apropiaciones de los modelos explicativos de la génesis del deporte moderno en el campo de la educación física.

\section{Los primeros pasos deportivos en Francia y Brasil}

Al iniciar su análisis sobre los primeros pasos del deporte en territorio francés, Terret expone las confrontaciones entre los métodos gimnásticos y los deportes. En ese momento de la obra son evocados autores como Georges Vigarello, Pierre Arnaud, Jacques Defrance y Gilbert Andrieu para explicar las contribuciones de las sociedades gimnasticas en el contexto francés. Dichas entidades tuvieron fuerte vínculo con los discursos higiénico y militar. En el fin de siglo XIX diversos clubes deportivos pasaron a competir con las entidades gimnásticas como forma de educar los cuerpos de los jóvenes, contribuyendo para la implementación y consolidación del deporte en el contexto francés, fenómeno que también ocurrió en el espacio escolar.

Esa disputa entre gimnasia y deporte se evidenció, en cierta medida, en tierras brasileñas. La confrontación ocurrió entre dos espacios institucionales diferentes, estuvo presente tanto en los clubes y asociaciones (Quitzau, 2010; 2019) como en torno de la disciplina escolar que posteriormente se convino en llamar Educación Física. Linhales (2009) afirma que el deporte participó del proyecto socioeducativo que pretendió transformar a la escuela en una referencia educacional moderna, especialmente a partir de la Asociación Brasileña de Educación (ABE), en 1924. En esa entidad fue formada una sección destinada a la educación física, y en ese espacio hubo enfrentamientos a favor de un sistema nacional de educación fisica, que tenía, de un lado, defensores de la visión medico pedagógica y, de otro, representantes de la perspectiva deportiva. Al dialogar la historiografía francesa con la brasileña se evidencia que, en la confrontación entre el deporte y la gimnasia, tanto en los clubes y asociaciones como en el formato de disciplina escolar, la propuesta deportiva fue la que acabó siendo la predominante (Linhales, 2009; Quitzau, 2010; 2019).

\section{anuario.}




\section{MARCELO MORAES E SILVA - DANIELE CRISTINA CARQUEIJEIRO DE MEDEIROS - EVELISE AMGARTEN QUITZAU - ALEJO LEVORATTI}

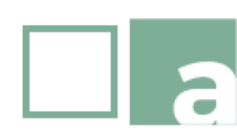

Terret indica que las sociedades de gimnasia no fueron los únicos agentes que buscaban frenar la difusión del deporte en Francia. La aristocracia y la alta burguesía, por considerar algunas prácticas deportivas, principalmente la esgrima y la equitación, como elementos de distinción, también frenaron la implementación de la novedad inglesa en el país. Recién a mediados del siglo XIX los primeros deportes comenzaron a ser practicados más allá de los círculos aristocráticos. Se destacan las carreras pedestres, el lawn-tennis, el patinaje, el remo y el tiro al blanco, que a partir del último cuarto de siglo XIX comenzó a ir acompañado el fútbol y el rugby.

A su vez, la difusión de las diversas modalidades deportivas, principalmente el fútbol y el rugby, se dio de la mano de los jóvenes estudiantes de Paris y de las ciudades universitarias como Bordeaux, Dijon, Grenoble, Lyon e Toulouse. Fue en ese contexto que el joven aristócrata francés Pierre de Coubertin se posicionó de modo enfático a favor del deporte como medio de educación de la juventud francesa. Es por ello que promovió una rivalidad con importantes nombres de la Educación Física francesa como Paschal Grousset, Phillipe Tissié y Fernand Lagrange. Todos ellos terminaran creando o influenciando en la fundación de instituciones específicas para la difusión de las prácticas deportivas en dicho país. En ese contexto surge en 1889 la Union des Societés Françaises de Sports Athlétiques (USFSA), institución que se inspiró en la británica Amateur Athletic Association y difundió el ideal amateur en el país.

En dicha secuencia se presentó información que indica el crecimiento del deporte en Francia. Terret apunta que en 1980 la USFSA contaba con 13 sociedades y 2.000 miembros, números que después de la Primera Guerra Mundial pasaron a 1.700 entidades y 300.000 asociados. Durante el cambio del siglo XIX para el XX, el deporte se extendió más allá de los espacios elitistas, surgiendo las primeras asociaciones de operarios, pudiéndose destacar la Fédération des Societés Athlétiques (1896) y la Fédération Gymnastique et Sportive des Patronages de France (FGSPF) fundada en 1898. En ese entonces ya se discutía las definiciones de amateurismo existentes en la USFSA. La FGSPF se tornaría, en 1907, la principal fuerza dentro del Comité Français Interfédéral (CFI), rompiendo la hegemonía de la USFSA en el fútbol francés.

Terret evoca nuevamente a la figura del barón Pierre de Coubertin, explorando las cuestiones que llevaron al aristócrata francés a idealizar a los Juegos Olimpicos Modernos. El aristócrata fundamentaba sus acciones en los principios de la paz social y la prosperidad de las naciones, aunque, luego de las primeras ediciones, los Juegos habian dado paso a los elogios de los poderes nacionalistas. La fuerte relación de Coubertin con la USFSA permitió sistematizar los juegos en torno al ideal del amateurismo, considerado esencial para su buen desarrollo. Fue sobre la figura del barón que innumerables federaciones internacionales deportivas fueron creadas.

\section{anuario.}




\section{Similitudes y diferencias en la historiografia del deporte en Brasil y Francia: un diálogo con "Histoire du sport" de Thierry Terret}

Posteriormente Terret explora cómo el deporte fue utilizado por las ideologías políticas emergentes en Europa después de la Primer Guerra. En este contexto, la prensa deportiva francesa, inglesa y estadounidense había comenzado a utilizar discursos que traducian las habilidades deportivas en capacidades bélicas, lo que indica que el buen deportista también sería un buen soldado.

Se evidenció además el surgimiento de un nuevo contexto institucional del deporte francés: desde los tiempos de la guerra había aumentado la crisis en la USFSA, haciendo que, después de 30 años de hegemonía, comenzara a sufrir pérdidas. En 1920 el rugby se separó de la entidad, creando la Fédération Française de Rugby (FFR). Otro factor que contribuyó para la derrota de la vieja institución fueron los resultados obtenidos en los Juegos Olímpicos de Amberes en 1920, por lo que en 1923 existian más de 30 federaciones deportivas independientes en Francia.

Otro punto analizado en la obra francesa fue la transformación de los eventos en espectáculos. Terret señala que la reestructuración del paisaje institucional se dio por la especialización, pero el mismo fue acompañado por la transformación del deporte como elemento de la cultura de masas. Si después de la Primera Guerra había 1 millón de practicantes, siendo 300.000 de fútbol, en 1939 los números eran de 4 millones, o sea, $10 \%$ de la población francesa del período. Los números son mayores si se tienen en cuenta a los espectadores y a los lectores de la prensa especializada. Los grandes eventos internacionales como la Copa del Mundo de Fútbol o los Juegos Olímpicos pasaron a ser cada vez más valorados en el escenario de las relaciones internaciones y muy utilizado en el plano politico. Para hacer esta afirmación, el autor retomó un trabajo anterior (Terret, 2008) y el libro escrito por Paul Diestchy, Yvan Gastaud y Sthepané Mourlane (2006), donde se estudiaron los Juegos Olimpicos de París en 1924 y la Copa del Mundo de Futbol en 1938.

Fue en el período de entre guerras que emergió la figura del campeón, pues sin vencedores no existía espectáculo y tampoco un fenómeno de identificación nacional con el deporte. Por eso ocurrió la "invención" de la figura de los héroes deportivos. E1 esgrimista Lucien Gaudin, el nadador Jean Toris, los corredores Jules Ladoumègue y Jean Giroudox, el equipo de polo acuático campeón olímpico de 1924, Suzane Lenglen y los "Mosqueteros" Jean Borotra, Jacques Brugnon, René Lacoste y Henri Cochet en el tenis y el boxeador Georges Carpentier fueron los mayores ídolos franceses del período. La figura del campeón ayudó a la llegada del profesionalismo y el derrocamiento del amateurismo, posibilitando una preparación más racional de los atletas que pasaban cada vez más a ser sustentando en posiciones científicas y dejando de lado los conocimientos empíricos de los entrenadores.

Otro punto enfatizado son los lugares del deporte, visto que con el desarrollo del deporte de masas y del profesionalismo, se acentuó la necesidad de espacios específicos. Tanto que en 1919 la Ley Cornudet obligaba a las ciudades a tener en su espacio urbano equipamientos deportivos. Muchas localidades comenzaron a

\section{anuario.}




\section{MARCELO MORAES E SILVA - DANIELE CRISTINA CARQUEIJEIRO DE MEDEIROS - EVELISE AMGARTEN QUITZAU - ALEJO LEVORATTI}

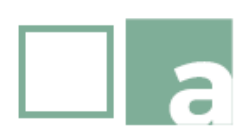

construir estadios y diversas arquitecturas fueron inventadas en virtud del prestigio de los espectáculos deportivos. Pasaron a existir también instituciones católicas, obreras, feministas y educativas que difundieron sus valores e intereses a través de las prácticas deportivas.

En Brasil, no hubo una vía única de desarrollo del deporte, lo que apunta a una cierta "distancia aproximada" de lo que ocurrió en el contexto francés. Al mismo tiempo que las prácticas que llegaron a tierras brasileñas eran inspiradas en las realizadas en Europa, había una producción de sentidos y significados propios atribuidos a estas manifestaciones en suelo brasileño. Se torna posible percibir, por tanto, que se hicieron innumerables adaptaciones y apropiaciones de las prácticas deportivas en el país.

Otra cuestión bastante pertinente fue la difusión regional que el deporte tuvo en un país de grandes dimensiones como Brasil. A pesar de que Río de Janeiro era la capital de la República, en el cambio de siglo XIX para el XX, momento en que los deportes llegaban y se establecían, el desarrollo de las prácticas deportivas en su territorio no es expresiva de la amplia gama de apropiaciones y adaptaciones deportivas existentes (Lucena, 2001; Melo, 2001). Hay una tendencia en algunos estudios brasileños de tomar las investigaciones sobre el Rio de Janeiro como afirmación del desarrollo deportivo en el país en su totalidad, lo que hace los análisis menos precisos e impide el entendimiento de las particularidades regionales. Sin embargo, aunque esta tradición busque reafirmarse, numerosos autores se han dedicado a investigar las especificidades del desarrollo deportivo en el país en áreas distintas de la ex capital federal.

Se puede pensar en el desarrollo de los deportes en algunas ciudades del sur del país, a través de trabajos como los de Moraes e Silva (2011; 2015), Moraes e Silva, Quitzau y Soares (2018), Furtado, Quitzau y Moraes e Silva (2018), Moraes e Silva y Quitzau (2018), Silva y Mazo (2017) y Silva, Mazo, Tavares (2018); en nordeste con Lucena (2010), Rocha Júnior y Espírito Santo (2011), Pires, Dias e Leite (2014) y Montenegro y Soares (2019); centro-oeste con Días (2018) y en el norte de Brasil con Dias y Soares (2014), Corrêa (2017) y Souza (2017). Estos trabajos señalan, cada uno a su manera, que, aunque se establecieron algunas similitudes en este proceso, hubo innumerables diferencias que marcaron las apropiaciones de las prácticas deportivas en cada región de Brasil, guiadas por sus propias configuraciones.

Con las diferencias regionales en mente, es posible decir que fue en la segunda mitad del siglo XIX cuando soplaron los primeros vientos deportivos en Brasil, especialmente a través de prácticas que ya se llevaban a cabo en el país, pero que fueron resignificadas, como es el caso de las carreras de caballos (Lucena, 2001; Melo, 2001; Moraes e Silva, 2011; 2015). Otras modalidades llegaron a través de los

\section{anuario.}




\section{Similitudes y diferencias en la historiografia del deporte en Brasil y Francia: un diálogo con "Histoire du sport" de Thierry Terret}

clubes y asociaciones que se instalaron, estimulados principalmente por la presencia de inmigrantes, que ya conocian las actividades deportivas en sus países de origen (Quitzau, 2010; 2019). Se estaba desarrollando una cultura física en el país, en la cual se establecieron varios discursos y prácticas relacionados con el cuerpo, basados en relaciones sociales, económicas, políticas, éticas y morales. El deporte era una de las expresiones de esa cultura física que se difundía en el Brasil.

Los primeros intentos de burocratización del deporte en el país fueron a través de las asociaciones de remo. En 1895, surgió en Rio de Janeiro la União de Regatas Fluminense, que tenía como objetivo reglamentar y fiscalizar la realización de pruebas (Cancella y Santos, 2012). A partir de ahí, se describen principios como las regulaciones internas, el código de prácticas deportivas, la ley de aficionados, las regulaciones para el uso de materiales y para las clases de competidores. La influencia de esta institución en la organización deportiva del remo es clara. Sin embargo, como señaló Sarmento (2013), una organización federativa más precisa en relación con el deporte se estableció solo en 1914, la Confederación Brasileña de Deportes (CBD), cuya misión era promover la práctica deportiva en el país de una manera más amplia y fue fundamental para la difusión del fútbol en el país.

En el período Vargas (1930-1945), se puede afirmar que existió, por primera vez, la intención de hacer del deporte y de la educación física una política de Estado en el Brasil (Horta, 1994; Drumond, 2014; Parada, 2009). Sin embargo, esta implementación no se inició inmediatamente en los primeros años de su gobierno, Vargas no actuó eficazmente en la representación deportiva. Prueba de eso fue que, en 1932, la comitiva brasileña para las Olimpiadas no dispuso del financiamiento gubernamental. Drumond (2014) subraya que fue durante este período que se gestaron disputas entre las federaciones brasileñas, alentadas principalmente por el debate entre amateurismo y profesionalismo. Los clubes de fútbol intentaron, a su manera, eludir las reglas de amateurismo impuestas por la CBD, o hacerlas menos rígidas dentro de la federación, pero sin éxito. Esas disputas generaron peleas y la formación de nuevas ligas que consideraban los intereses de los clubes, especialmente en el fútbol.

Drummond (2014), argumenta que esa situación se comenzó a modificar cuando, en la selección de los atletas para disputar la Copa del Mundo de 1934, la CBD (única entidad brasileña afiliada a la FIFA) tuvo que renunciar al amateurismo al contar con jugadores que eran pagos en equipos que no formaban parte de la confederación. En poco tiempo, el profesionalismo se tornó la forma hegemónica en el fútbol en Brasil, hecho que no pudo ser evitado por la CBD. Aunque la cuestión del amateurismo fuera superada, las peleas entre los grupos y entidades por el control de los deportes no habían terminado. La CBD era una entidad que albergaba tanto a las federaciones regionales generalistas, como fue el caso de la Federación Deportiva Riograndense, como a las especializadas en un solo deporte, como la Federación Brasileña de Remo. En 1935, las federaciones especializadas se unieron y decidieron formar el Consejo 


\section{MARCELO MORAES E SILVA - DANIELE CRISTINA CARQUEIJEIRO DE MEDEIROS - EVELISE AMGARTEN QUITZAU - ALEJO LEVORATTI}

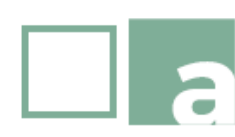

Nacional de Deportes, con el fin de unificar sus fuerzas para combatir el CBD. Esta disputa tuvo un nuevo capítulo cuando, en vísperas de los Juegos Olímpicos de 1936, entidades especializadas se acercan al Comité Olímpico Brasileño (COB). Esta entidad, que estaba ganando nuevos poderes, no fue aceptada por la CBD, que también tenía la intención de enviar su delegación a los Juegos. Con la intervención directa de Vargas, las federaciones llegaron a un acuerdo y lograron participar en los Juegos Olimpicos (Souza, 2008).

Drummond (2014) indica que los intereses de Vargas en el deporte crecieron cuando se dio cuenta de su poder en la población juvenil y en las masas. Esto se expandió después del éxito del equipo brasileño en la Copa del Mundo de 1938. En ese año, los atletas brasileños, que llegaron en tercer lugar, fueron aclamados como los "ganadores morales" de la competencia celebrada en Francia, y se formó una conmoción nacional en torno a este deporte y la figura heroica de Leónidas da Silva, apodado "Diamante Negro", comenzó a ser exaltada. A partir de esta experiencia, el gobierno creó varios decretos con el objetivo de regular y controlar los deportes. Como resultado, la explotación política del deporte, especialmente el fútbol, tomó forma y se convirtió en un aparato para la difusión de la ideología del Estado Novo. Horta (1994) y Parada (2009) argumentan que Vargas realizó varias presentaciones públicas en estadios de fútbol, que cada vez ganaban más protagonismo en el país, y difundió sus mensajes en estos espacios siempre atestados de público.

\section{Los usos politicos del deporte}

Otro punto explorado por Terret fue la relación entre deporte y Estado, que, así como en otros países (Arnaud y Riordan, 1998; Krüger, 2015; Bolz, 2008; 2016) estuvo bastante presente en el escenario francés durante el siglo XX. El autor analizó el proceso de conquista de las masas ocurrido entre los años 1939 a 1975. Un régimen autoritario, dos repúblicas y el fin del imperio colonial francés marcaron ese período de la historia de Francia, que evidenció el control total del Estado sobre el deporte.

Un primer momento tuvo lugar durante la Segunda Guerra Mundial, cuando el territorio francés fue ocupado por las tropas nazistas. El país, que había sido derrotado y divido en dos zonas, instaló un nuevo gobierno en Vichy a través del mariscal Philippe Pétain, que se atribuyó plenos poderes, modificando la constitución y estableciendo un mando autoritario y colaboracionista al gobierno alemán. La derrota militar y la responsabilidad de regresar al frente sirvieron de pretexto para la restauración de principios como la disciplina y el entrenamiento de los hombres de acción. La lucha contra la decadencia de las costumbres y valores tradicionales del pueblo francés fue retomada y resumida en el lema de la época: "Trabajo, familia y

\section{anuario.}




\section{Similitudes y diferencias en la historiografia del deporte en Brasil y Francia: un diálogo con "Histoire du sport" de Thierry Terret}

patria". En este espíritu, el deporte y la educación física desempeñaron un papel decisivo en el proceso de formación de los jóvenes franceses. El ex mosquetero de tenis francés Jean Borotra se convirtió en un importante burócrata estatal y terminó estableciendo una relación reguladora entre el estado y el deporte. El exatleta impuso una ideología relacionada con el principio moral de la "revolución nacional", inhibiendo la libertad de asociación y estableciendo una dependencia tutelar entre el estado y el deporte.

Aquí, nuevamente, es necesaria una aproximación al período Vargas en Brasil. En ese momento, el deporte se institucionalizó y el gobierno comenzó a ejercer control sobre la práctica. Los quince años de la "Era Vargas" se destacaron por una serie de reestructuraciones en el escenario brasileño. La estrecha relación con las masas, un elemento emergente en la cultura política brasileña, acercó el fútbol y el samba a un proyecto gubernamental que tenía la intención de producir una nueva imagen nacional (Drumond, 2014; Parada, 2009).

Horta (1994), Parada (2009) y Drumond (2014) indican que, en el ámbito político, la creación de la División de Educación Física, vinculada al Ministerio de Educación y Salud Pública, y la promulgación del Decreto Ley N³.199/41, que estableció las bases para la organización del deporte en el país, pueden ser considerados como los marcos principales del control estatal sobre el deporte. Drumond (2014) señala que el decreto mencionado tuvo un profundo impacto en la estructura del deporte brasileño, especialmente en lo que respecta a la regulación de las entidades deportivas, la definición del papel del Estado en relación con el deporte y la indicación de cómo administrar sus prácticas. La norma pretendía llevar a cabo un modelo de gestión que controlase las prácticas deportivas en el territorio nacional, con el Consejo Nacional de Deportes y la Confederación Brasileña de Deportes como entidades centrales.

De la misma manera que Terret destacó el periodo de Vichy en Francia, ocurrió en Brasil una contribución del deporte para la construcción del "espíritu nacional" y eso solo sería posible con la intervención directa del gobierno. En este sentido, la educación física y el deporte, como lo señalaran Horta (1994) y Parada (2009), presentó nuevos horizontes para la educación de la población, ya que podrían contribuir no solo al desarrollo biológico, sino, sobre todo, al ajuste social y la mejora moral de los individuos.

Después de analizar el período de Vichy, Terret comienza a explorar lo que llamó los "Treinta Gloriosos", que van desde la época de la Liberación hasta mediados de la década de 1970 y que estuvieron marcados por un aumento cuantitativo en los números relacionados con el deporte. El libro proporciona datos empíricos para mostrar este crecimiento, ya que Francia, en 1949, tenía 1,8 millones de practicantes, llegando a 5,2 millones en 1970 y 7,4 millones en 1975. Una serie de cuestiones hicieron posible este gran volumen de practicantes, como el fortalecimiento de las

\section{anuario.}




\section{MARCELO MORAES E SILVA - DANIELE CRISTINA CARQUEIJEIRO DE MEDEIROS - EVELISE AMGARTEN QUITZAU - ALEJO LEVORATTI}

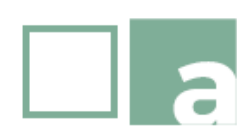

instituciones que difundieron la gimnasia voluntaria, las ligas católicas y socialistas, la Ligue Girondine y la Federación Hébertiste y el fortalecimiento de las acciones de las entidades que difunden el deporte entre las personas con discapacidad. Sin embargo, el elemento más importante de esta evolución fue el aumento en el deporte no institucional que ocurrió en la década de 1960. La práctica deportiva gana una audiencia que nunca había alcanzado.

Los factores explicativos planteados por el autor para interpretar este aumento en el número de practicantes se toman de la combinación de numerosas razones culturales, económicas, demográficas y politicas que ocurrieron en Francia en los años sesenta y setenta. Los principales elementos son los siguientes: a) un gran número de jóvenes que representaban, a fines de la década de 1960, un tercio de la población francesa; b) fuerte progresión en el nivel de vida, una cuestión que permitió más tiempo libre para la población, creando lo que Joffre Dumazedier llamó "civilización de ocio"; c) expansión de las ofertas de práctica deportiva en escuelas, plazas y otros espacios para la población; d) creación de programas para el mantenimiento de espacios y equipos deportivos y de actividades socio-educativas; e) mayor presencia de mujeres en actividades deportivas f) adopción de un modelo de educación física en la escuela más orientada al deporte. Estos factores fueron los elementos que culminaron en un mayor proceso de democratización del deporte en el contexto francés.

Este punto también estuvo presente en el escenario brasileño, ya que a fines de la década de 1960 el gobierno cívico-militar (1964-1985) produjo el "Diagnóstico de Educação Física e Esporte no Brasil" (Dacosta, 1971). Fue la primera vez en el país que se realizó un estudio más amplio sobre la realidad deportiva. La investigación llegó a conclusiones que fueron fundamentales para el desarrollo del deporte en el país, principalmente al señalar las graves deficiencias estructurales. La sugerencia general del Diagnóstico fue cambiar la legislación vigente desde el período Vargas, que se consideró el principal obstáculo para la modernización del deporte en Brasil.

Navarro (2020) y Navarro, Mezzadri y Moraes e Silva (2020) señalan que fue en este período dictatorial y militar que se produjo el inicio del proceso de preocupación del gobierno brasileño sobre otras dimensiones que iban más allá del deporte de élite, apareciendo las primeras acciones por parte del estado con relación al deporte educativo y de participación. Sin embargo, esta diversificación no eliminó el predominio de los deportes de rendimiento. Los autores sostienen que fue el discurso sobre el deporte de participación lo que insertó un discurso sobre la valorización del deporte como un derecho social en el país, ya que en la década de 1970 se estaba implementando en Brasil el proyecto "Deporte Para Todos".

\section{anuario.}




\section{Similitudes y diferencias en la historiografia del deporte en Brasil y Francia: un diálogo con "Histoire du sport" de Thierry Terret}

Otro punto analizado por Terret sobre el deporte y la política fue la relación entre deporte y la Guerra Fría. Después de la división del mundo en dos bloques, en 1945, la performance deportiva se transformó en un elemento de demostración de las cualidades de cada modelo social. Terret recuerda que Francia también fue afectada por esa ideología política, principalmente después de la humillante participación de la delegación francesa en las Olimpiadas de 1960 en Roma, donde los tricolores lograron solamente cinco medallas. Charles de Gaulle, que había instalado en 1958 la Quinta República, asumió como presidente en 1959, cargo que ejerció hasta 1969. De Gaulle tenía la ambición de constituir a Francia en una alternativa al poder mundial dividido entre Estados Unidos y la Unión Soviética, y el deporte de rendimiento estaba en ese programa. Por ello, el financiamiento deportivo fue aumentando y toda la administración deportiva del país se reorganizó. Se centralizó en el Institut National des Sports lo inherente a los directores técnicos nacionales, consultores regionales y departamentales para las federaciones deportivas y la preparación olímpica.

Se puede decir en cierto sentido que el gobierno militar brasileño intentaba realizar acciones de fortalecimiento del deporte de rendimiento, así como lo hizo de Gaulle en Francia. Al final, conforme a lo expresado por Navarro (2020) y Navarro, Mezzadri y Moraes e Silva (2020) los militares, a pesar de haber insertado otras manifestaciones deportivas en el ordenamiento deportivo brasileño, terminaron fortaleciendo las estructuras del deporte de rendimiento en el país.

Lo señalado sobre el papel del Estado en el ámbito deportivo francés se hizo en base a la prescripción de 1945 y la Ley de Mazeaud promulgada en 1975. Después de la Liberación, el Estado francés se dividió en dos posiciones en relación con el deporte: a) su uso como elemento de reconocimiento del país; b) mantenimiento de la creencia en su valor educativo. Estas dos intenciones resultaron ser las razones de la prescripción de 1945 para mantener el control estatal sobre el plan deportivo, lo que demuestra que la nueva disposición legal era una continuación de lo que se había establecido bajo el gobierno de Vichy. En ese momento, se creó un sistema que hizo del deporte un servicio público, donde las dimensiones educativas, de masas y el rendimiento revelaron una lógica complementaria y los municipios comenzarían a jugar un papel importante en la difusión del deporte en toda Francia.

En virtud de ese desarrollo, en octubre de 1975 fue establecida la Ley Mazeaud, propuesta por Pierre Mazeaud entonces secretario de la Juventud y Deporte. La disposición legal reafirmaba que el desarrollo deportivo era una obligación estatal. Otro elemento importante que fue colocado en la legislación era la creación del Institut Nacional du Sport et de l'Education Physique (INSEP), Fondo Nacional de ayuda al Deporte de Alto-Rendimiento y la inserción universitaria proporcionada por la creación de la Sciences et Techniques des Activités Physiques et Sportives (STAPS). La ley, a pesar de mantener la tutela estatal, pasó a dividir un poco más el control del

\section{anuario.}




\section{MARCELO MORAES E SILVA - DANIELE CRISTINA CARQUEIJEIRO DE MEDEIROS - EVELISE AMGARTEN QUITZAU - ALEJO LEVORATTI}

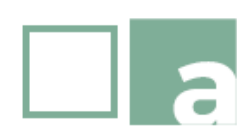

deporte con las federaciones deportivas, indicando un mayor impulso liberal por parte del gobierno francés.

Este movimiento en Brasil fue posterior, ocurrió en la década de 1980, cuando la promulgación de la Constitución Federal de 1988, sumado a la consolidación de la producción académica en Educación Física, ayudó a instaurar el deporte como un derecho social en el texto constitucional. Sin embargo, como en Francia, el estado brasileño, conforme lo expresado por Mezzadri et al. (2015), Moraes e Silva y Loudcher (2020) y Navarro (2020), también promovió un mayor impulso liberal en el deporte, otorgando a las entidades deportivas una mayor autonomía debido a los intereses derivados del fútbol profesional.

El último punto analizado se refiere a la celebración de importantes eventos internacionales en suelo francés. Terret indica que Francia, desde la década de 1990, fue uno de los principales países en albergar importantes eventos deportivos. Esta densidad no se debe al azar, ya que organizar mega eventos asegura una ganancia de notoriedad simbólica que puede proporcionar un retorno económico, turístico, aceleración en la construcción de equipamientos deportivos e infraestructura urbana e incluso un posible aumento en el desarrollo de la práctica deportiva. El autor argumenta que, a pesar de estos varios puntos positivos, existen numerosos errores y fallas. Para ejemplificar cita como ejemplo lo que ha estado sucediendo en los preparativos para la organización de los Juegos de París en 2024.

Nuevamente, hay una proximidad a Brasil, ya que, como lo señaló DaCosta (2016), el país también pasó por la llamada década de los mega eventos deportivos. En ese momento, un gran número de investigadores vio una oportunidad para reflexionar sobre los principales eventos deportivos que el país comenzó a albergar. Se destaca especialmente la Copa Mundial de Fútbol 2014 y los Juegos Olimpicos de 2016. Los investigadores en antropología, estudios de ocio, geografia, sociología e historia reflexionaron sobre el tema, amplificando considerablemente este debate y llevándolo incluso fuera de las fronteras brasileñas en un proceso de mayor internacionalización de la producción nacional.

\section{El hacer historiográfico en la historia del deporte en Francia y Brasil}

La última gran temática abordada por Terret fue la discusión sobre el hacer historiográfico, recuperando el momento en que el deporte pasó a ser parte de los intereses de la historia. Para eso, el autor realizó, en un primer momento, un análisis de la historiografia del deporte mundial, indicando sus inicios en Estados Unidos en la década de 1950 y la emigración a Francia a mediados de los años 1960.

\section{anuario.}




\section{Similitudes y diferencias en la historiografia del deporte en Brasil y Francia: un diálogo con "Histoire du sport" de Thierry Terret}

Este interés en el deporte como objeto historiográfico estuvo en parte relacionado con la explosión del fenómeno deportivo en todo el mundo, a medida que los medios de comunicación comenzaron a difundir las competiciones deportivas a un público cada vez más amplio. Otro elemento recuperado por el autor se refiere a los cambios que ocurrieron en el espacio universitario después de los eventos del mayo de 1968, pues tal acontecimiento posibilitó que nuevos objetos, como el deporte y el ocio, pasen a ser dignos de atención por parte de los investigadores vinculados a las grandes universidades francesas.

Todo este movimiento que tuvo lugar desde la década de 1960 provocó que la Educación Física francesa atravesara una grave crisis de identidad que llevó a parte de sus profesores a regresar al espacio universitario para cuestionar los fundamentos y los orígenes de su disciplina escolar. Después de 1978, fueron defendidos diversos trabajos académicos con esa nueva perspectiva. Fue en ese contexto, de finales de los años 1970 y el inicio de los 1980, que emergió un grupo de investigadores que se especializaron en hacer historia de la educación física y de los deportes en el contexto francés.

Para explicar ese grupo, Terret aporta cuatro grandes divisiones. El primero compuesto por historiadores de formación y los principales objetos explorados por ellos fueron el olimpismo y determinados deportes, principalmente los más populares, como el ciclismo analizado por Philippe Gaboriau, el rugby investigado por Jean-Pierre Bodis y el fútbol estudiado por Alfred Wahl. En el segundo grupo se referencia a historiadores de la educación fisica que fueron beneficiados por la integración universitaria de la formación en Sciences et Techniques des Activités Physiques et Sportives (STAPS) y de un número creciente de docentes integrados a ella, cita como ejemplo a Gilbert Andrieu y Pierre Arnaud.

La tercera tipología explorada se refiere a la influencia del sociólogo Pierre Bourdieu. El autor indica que, a partir de la publicación del texto "¿Cómo se puede ser deportista?, en 1980, las reflexiones bourdianas se inscribieron en la agenda de investigación de la historia del deporte en Francia, promoviendo nombres importantes como el de Christian Pociello e Jacques Defrance. El último grupo se inspiró en las reflexiones de Michel Foucault para realizar una historiografia de las prácticas corporales. Terret indica que nombres como Daniel Denis, Jean-Marie Brohm, Michel Bernard y Georges Vigarello fundaron la revista "Quel Corps", que se tornó en un importante lugar de divulgaciones de trabajos sobre la historia del cuerpo, de sus usos y representaciones, y rápidamente integró la cuestión de los deportes en sus perspectivas, como, por ejemplo, en la propagación de los trabajos de André Rauch y Jacques Thibault.

Después de la constitución y el fortalecimiento de esos cuatro grandes grupos, la historia de los deportes se transformó en un objeto extremadamente variado, tanto que, en la década de 1990, pasó a tener una gran influencia de la historia cultural.

\section{anuario.}




\section{MARCELO MORAES E SILVA - DANIELE CRISTINA CARQUEIJEIRO DE MEDEIROS - EVELISE AMGARTEN QUITZAU - ALEJO LEVORATTI}

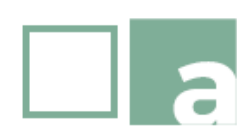

Para Terret y Froissart (2013) eso posibilitó una explosión cuantitativa y cualitativa, pues amplió considerablemente los archivos analizados, la renovación de las problemáticas, una mayor internacionalización de las perspectivas, la aparición de nuevos objetos y la utilización de diferentes modelos de análisis.

Se pueden encontrar aproximaciones y distanciamientos con esa tipología promovida por Terret al analizar las producciones brasileñas. Melo (1999) al hacer una Historia de la Historia de la Educación Física y del Deporte en el Brasil divide la misma en tres fases. La primera de ellas caracterizada por su carácter embrionario; se destacaron los trabajos de Laurentino Lopes Bonorino y colaboradores, de 1931, y Fernando de Azevedo, originalmente publicado en 1920, pero conocido después en 1960. Melo (1999) indica que ambos autores tenían sus preocupaciones centradas en los aspectos históricos de la gimnasia como una forma de "educación física". En esas obras existe una concepción historiográfica que impregnaria la producción brasileña, marcada por el uso restringido de fuentes. Además, hay un carácter militante que usa la historia como un instrumento para probar y legitimar algo previamente establecido, con una preocupación exacerbada por las fechas, nombres y hechos, enfocándose en la experiencia de grandes exponentes. En suma, una Historia que no buscaba una periodización interna, prefiriendo vincularse a periodizaciones políticas generales y trazadas superficialmente en largos períodos. Melo (1999) recuerda que la concepción histórica presente en esta fase tenía una función descriptiva-fáctica, mostrándose más cercana a la historia tradicional y muy alejada de la tradición de la "Nueva Historia" que surgía en el contexto europeo en ese mismo período.

La segunda fase presentada por Melo (1999) está marcada por el comienzo de una producción más preocupada por estudios históricos menos factuales. En ese sentido, el autor resalta la importancia de las obras de Inezil Penna Marinho y Jayr Jordão Ramos, destacando al primero de ellos. Castellani Filho (1988), Melo (1999) y Dalben (2011), indican que la influencia de Marinho fue tan grande que llegó a homogenizar los abordajes sobre Historia de la Educación Física en Brasil. Melo (1999) señala que el trabajo de Inezil Penna Marinho no significó una ruptura total con la fase anterior, pero según el autor, estuvo marcado por una diferencia significativa, principalmente con respecto a la profundidad teórica del enfoque historiográfico utilizado por el autor. Melo (1999) indica que el trabajo de Inezil tiene una calidad metodológica y que la labor realizada por el intelectual puede enmarcarse como un buen ejemplo de cómo escribir una historia tradicional en estándares documentales-fácticos. Oliveira et al. (2015) argumenta que en sus primeros trabajos hubo una fuerte relación con la "Escuela Metódica", principalmente en su libro "Contribuições para a história da Educação Física no Brasil" publicado en 1943 y en los cuatro volúmenes de "História da Educação Física e Esportes no Brasil: Brasil Colonia - Brasil Império - Brasil República", publicado entre los años 1952 a 1954.

\section{anuario.}




\section{Similitudes y diferencias en la historiografia del deporte en Brasil y Francia: un diálogo con "Histoire du sport" de Thierry Terret}

El tercer período estuvo marcado por la búsqueda de redimensionar las características de los estudios desarrollados en las dos fases anteriores a partir de una aproximación desde la teoría marxista, en la que se destacan los trabajos de Castellani Filho (1988) y Ghiraldelli. Júnior (1988). Estas son producciones de una naturaleza muy panorámica y que buscaban contrarrestar la historia oficial de Educación Física en Brasil, que todavía estaba muy marcada por las contribuciones de Fernando de Azevedo e Inezil Penna Marinho. Melo (1999) destaca el trabajo de Castellani Filho (1988), en el que el subtítulo se llama "la historia que no se cuenta", un libro en el que el autor intentó enfatizar la revelación de los aspectos ideológicos que estaban detrás de la trayectoria histórica de la Educación Física brasileña.

Aunque los trabajos de esta fase fueron un cambio significativo, algunos problemas de las fases anteriores continuaron siendo bastante evidentes. La temporalidad continuó estando sujeta a periodicidades exteriores al objeto; aprobó la linealidad histórica presente en las dos fases anteriores; se entendió la historia como responsable de la explicación lineal del presente, un hecho que se vio agravado por una comprensión que partía con hipótesis previamente establecidas y confirmadas, que prácticamente forja en el pasado los elementos necesarios para probar la hipótesis inicial; y la dura crítica del carácter documental-fáctico a menudo ha llevado a una dispensación de fechas, nombres y hechos, tan importantes para cualquier estudio historiográfico.

Taborda de Oliveira (2007) corrobora estas declaraciones. Para el autor, la década de 1980 estuvo marcada por el desarrollo de una nueva mirada sobre la Educación Física, basada principalmente en la llegada de las teorías críticas al campo educativo brasileño. Del contacto con estos estudios, se produjo una gran cantidad de investigaciones que señaló la "crisis" en la Educación Física brasileña, clasificada como una práctica sin legitimidad, sin una función social o educativa. Para denunciar esta crisis, varios autores se sumergieron en la historia de la disciplina, indicando líneas de continuidad entre lo que había sido y lo que fue la Educación Física después del período militar. Para el autor, el principal problema con estas investigaciones fue que estaban escritas a la luz de los determinantes estructurales, que no capturaron la lógica del proceso que existe en el desarrollo histórico. Por lo tanto, estas críticas se guiaron, en general, por una mirada generalizada y abstracta de los problemas históricos de la Educación Física brasileña, un examen que estaba más preocupado por lo que había afuera del espacio escolar que por la realidad que realmente lo rodeaba.

Melo (1999) señala que los estudios de Carmem Lúcia Soares y Silvana Vilodre Goellner, se estaban finalizando en el momento de la producción del texto de referencia, ya anunciaban un cambio de postura más cercano a la "Nueva Historia", a pesar de presentar características similares a la tercera fase. Se utilizan aquí los análisis de Melo (1999), pues este fue uno de los pocos trabajos que intentaron llevar a cabo una historia de la historiografia de la educación física en Brasil. Sin embargo, 


\section{MARCELO MORAES E SILVA - DANIELE CRISTINA CARQUEIJEIRO DE MEDEIROS - EVELISE AMGARTEN QUITZAU - ALEJO LEVORATTI}

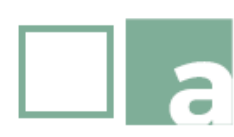

ya se han pasado más de 20 años desde la publicación de sus análisis, y la producción historiográfica brasileña ha elaborado numerosas investigaciones en el período posterior al texto de Melo. Por lo tanto, el relevamiento que se hace en esta investigación busca identificar y sistematizar las producciones en Historia de la Educación Física y del Deporte en Brasil de las dos últimas décadas que, consecuentemente, van más allá de la división propuesta por Melo (1999).

Un primer grupo que podría ser indicado estaría compuesto por historiadores de formación que seleccionaron el deporte, especialmente el fútbol, como objeto de investigación, como Ademir Gebara (UNICAMP), Leonardo Affonso de Miranda Pereira (PUC/RJ) y Luiz Carlos Ribeiro (UFPR). Dichos autores aportaron a los estudios historiográficos del deporte nuevas perspectivas desde la Historia y la Sociologia, insertando en Brasil nuevos enfoques y referencias como los de la Historia Social y una sociología configuracional, así como las contribuciones de autores como el inglés Edward Palmer Thompson y Eric Hobsbawn, el alemán Norbert Elias y el francés Pierre Bourdieu.

Una segunda clasificación podría ser la vinculada a una Historia de la Educación, que investiga la constitución histórica de la Educación Física en los procesos escolares. Generalmente compuesto por profesores de Educación Física que incorporaron diferentes problematizaciones del campo de la Historia (Historia Social e Historia Cultural) y referencias de los más variados historiadores ingleses (Thompson y Hobsbawn) y franceses (Certeau y Chartier), así como preguntas de la historia de la educación. Algunos nombres que se pueden mencionar son Marcus Aurélio Taborda de Oliveira y Tarcísio Mauro Vago, ambos vinculados a la Universidad Federal de Minas Gerais.

Otro grupo también está formado por historiadores del deporte que investigan tanto la Educación Física en cuanto disciplina escolar como la gimnasia y el deporte en general. Se destacan Amarílio Ferreira Junior (UFES), Andrea Moreno (UFMG), Carmen Lúcia Soares (UNICAMP), Janice Zaperllon Mazo (UFRGS), Silvana Vilodre Goellner (UFRGS) y Víctor Andrade de Melo (UFRJ). Todos estos autores trabajan con perspectivas muy variadas, con diversos objetos y con una amplia gama de fuentes de investigación, lo que demuestra que una historiografia de Educación Física y Deportes en Brasil se ha consolidado de manera muy fuerte y contundente.

Un segundo elemento planteado por Terret se refiere a objetos y métodos. El autor indica que la producción de los investigadores en la década de 1990 estaba menos preocupada por el problema de identidad de la Educación Física y más interesada en la Historia del Deporte. Los objetos más explorados fueron los vinculados a la génesis y transformación de la institución deportiva. Sin embargo, estos estudios estuvieron generalmente acompañados y dominados por lecturas políticas sobre el fenómeno

\section{anuario.}




\section{Similitudes y diferencias en la historiografia del deporte en Brasil y Francia: un diálogo con "Histoire du sport" de Thierry Terret}

deportivo (niveles local, nacional e internacional). En un análisis más global, el autor señala que existe una tendencia reciente y estimulante que explora los fenómenos de transferencia cultural.

Las relaciones permanecen muy presentes con muchos análisis centrados en la noción de ideología (política, espiritual, educativa). A diferencia de las producciones de la Historia del Deporte de América del Norte, la historiografia deportiva francesa aún no ha abordado problemas como los raciales, el colonialismo o la historia de la inmigración. Un fenómeno similar ocurre con la categoría de género, que recientemente ha sido estudiada por historiadores del deporte en Francia.

Un tema que también destacó el autor se refiere a la dificultad de producir estudios basados en una historia cultural del deporte. Debido a la gran diversidad de temas cubiertos, es muy dificil llevar a cabo una investigación estricta con este tipo de enfoque historiográfico, lo que indica que estas aproximaciones intermedias como la historia de las pedagogías deportivas, los espacios y los equipamientos tienen la capacidad de presentar elementos más allá de una historia económica, política o social.

El último punto explorado está relacionado con los historiadores del deporte. En este punto, el autor subraya que las primeras asociaciones de historiadores del deporte no son de carácter nacional, sino de dimensiones internacionales. En 1967 se fundó el International Committee for The History of Physical Education y en 1973 la International Association for The History of Physical Education and Sport. Ambas entidades tenian aspiraciones mundiales; la primera agrupaba investigadores del bloque oriental y la segunda de historiadores occidentales.

También se analizaron las asociaciones norteamericanas. El autor menciona la creación de revistas y entidades propias, citando como ejemplo la fundación en 1969 de The Canadian Journal of History of Sport and Physical Education, transformada en 1995 en Sport History Review. En 1972, se creó la North-American Society for Sport History, una asociación científica fundada por estadounidenses y canadienses que organiza anualmente un congreso y que después de 1974 comenzó a publicar una de las principales revistas especializadas, el Journal of Sport History. Por otra parte, en el otro lado del Atlántico, en ese momento, no había una organización equivalente en torno a las publicaciones periódicas. Una de las pocas iniciativas fue a través de los historiadores alemanes que crearon la revista Stadion en 1975. En la década de 1980, la situación cambió por completo en suelo europeo. Varios países crearon sus asociaciones nacionales. La British Society of Sport History se fundó en 1982 y en 1987 se lanzó la Societé Française d'Histoire du Sport, que fundó en 1988 la revista Sport-Histoire. Sin embargo, este periódico no consigue estabilizarse y se relanzó en 2003 con un nuevo nombre: Science sociales et sport. La publicación ya no se limita a la historia, sino que también se articuló con los sociólogos del deporte. Los historiadores del deporte en Francia todavía tenían un espacio editorial limitado, ya

\section{anuario.}




\section{MARCELO MORAES E SILVA - DANIELE CRISTINA CARQUEIJEIRO DE MEDEIROS - EVELISE AMGARTEN QUITZAU - ALEJO LEVORATTI}

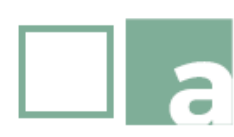

que las opciones eran revistas de historia más generales o publicaciones multidisciplinarias de ciencias del deporte como STAPS.

En competencia con Stadion y el Journal of Sport History, en 1984 surge el International Journal of the History of Sport, creado por iniciativa del británico James A. Mangan, que más tarde se convertiría en la revista más prestigiosa del área. Otro punto mencionado por el autor fue la unificación en 1989 de la International Committee for The History of Physical Education y la International Association for The History of Physical Education and Sport, creando asi una nueva asociación internacional: International Society for The History of Physical Education and Sport. Terret también menciona la creación de asociaciones en Asia, América del Sur, Australia, así como el establecimiento en 1995 del Comité Européen d'Histoire du Sport. La mayoría de estas entidades promovieron sus congresos y revistas para desarrollar la historiografia del deporte en estas regiones.

La última pregunta planteada por Terret hace referencia a la indiferencia que los historiadores franceses tuvieron hacia el deporte como objeto historiográfico. Esto comenzó a cambiar con la legitimación del deporte en la sociedad francesa. Con eso, una apertura tímida fue establecida, que se puede ver en las principales revistas de historia, en los temas de tesis y en un mayor diálogo entre universitarios de STAPS con los historiadores. El autor afirma que este enfoque tiene sus límites, lo que dificulta que el deporte alcance el mismo estatus que otras prácticas como objeto de estudio en la historiografia contemporánea.

Esta realidad evidenciada por Terret en relación con Francia encuentra ecos aún más evidentes en Brasil, ya que no hay entidades específicas destinadas a la Historia del Deporte, y fue recién en 2008 que se creó la primera revista específica de História do Esporte (Record). La mayor aproximación son los grupos de trabajo dentro de entidades más amplias, como el Colégio Brasileiro de Ciências do Esporte y la Associação Nacional dos Professores Universitários de História. Además de estas propuestas, hay un evento llamado Congresso de História do Esporte, do Lazer e da Educação Física, que se creó en 1993 con su 15a edición celebrada en 2018 en la ciudad de Curitiba.

La falta de revistas específicas compromete, en parte, la difusión de los trabajos de investigadores en el área que, así como en el contexto francés, publican sus investigaciones en revistas difundidas en las áreas de Educación Física, Educación e Historia. Hay una mayor presencia de publicaciones en revistas en el área de Educación Física por dos razones. Uno, la relativa diseminación de estas revistas en Brasil, que existen en gran número. La segunda razón es que esta temática, especialmente cuando lo llevan a cabo investigadores del campo de la Educación Física, todavía es vista con cautela por los historiadores.

\section{anuario.}




\section{Consideraciones finales}

En síntesis, este artículo se centró en una de las obras del estudioso del deporte francés, Thierry Terret, para buscar relaciones entre la historia del deporte francés y brasileño. El trabajo es bastante amplio en términos de comprensión de la historia del deporte en Francia. Esto significa que no se limita a contar las historias del desarrollo deportivo en tierras francesas propiamente dicha, sino que también aporta otros elementos que forman parte de esta comprensión, como las afiliaciones y las corrientes de pensamiento sobre la historia del deporte y el desarrollo de la historiografia francesa sobre este tema. Fue posible, por lo tanto, establecer paralelos con respecto a las afiliaciones teóricas y el desarrollo del campo de la historiografia; al mismo tiempo, pensando en cómo el deporte llegó a estos países y se estableció, enfrentándose a la oposición y ganando aliados durante todo el proceso.

Por lo tanto, se observa que, con respecto a la historia de las ideas sobre el deporte, Francia y Brasil están muy cerca. Los autores compartieron sus trabajos en ambos países, la elaboración historiográfica se acercó a ciertas corrientes teóricas de una manera más o menos concomitante y las influencias en el pensamiento y el desarrollo del campo fueron, de alguna manera, compartidas. Esto probablemente se debió a la influencia y receptividad que las ideas de los pensadores franceses en el campo deportivo tenían en Brasil.

Sin embargo, el segundo modelo de análisis, aquel que colocó en evidencia el desarrollo del deporte en el país a lo largo del período abarcado en la obra, se alejó más de los modelos brasileños. Esto sucedió, como se señaló en la investigación, debido a las especificidades y particularidades brasileñas en asuntos históricos, geográficos y sociales, que delinearon formas muy particulares de "ser deportista" en Brasil.

Se estableció una amplia relación entre la historia del deporte francés y la de Brasil. Con eso, se trató de mostrar que, aunque hay particularidades en estos procesos, muchos discursos se amalgaman. Las acciones historiográficas y los enfoques teóricos son cuestiones que, según se analizan, combinan muchas similitudes, incluidas algunas influencias. Por otro lado, es posible notar que los hilos de la historia del deporte no siempre se conectan, y hay muchas particularidades geográficas, políticas y estructurales que merecen sus propias narrativas. Se concluye que conocer la historia del deporte de otros países, especialmente Francia, uno de los grandes exponentes del tema, es una forma potencial de conocer la historia del deporte brasileño y sudamericano.

\section{Bibliografia}

\section{anuario.}


Attali, M.; Robene, L. (2015). Le corps comme objet de pensée critique: JeanMarie Brohm et la critique radicale de l'éducation physique sportive. In. Attali et al. La pensée critique des enseignants: éléments d'histoire et de théorisation. Rouen et Havre: Presses Universitaires de Rouen et du Havre, 167-188.

Arnaud, P y Riordan. J. (1998). Sport and international politics: the impact of fascism and communism on sport. London: E\&FN spon.

Bolz, D. (2016). Sport and fascism. Routledge Handbook of Sport and Politics, 83-93.

Bolz, D. (2008). Les arènes totalitaires. Fascisme, nazisme et propagande sportive. Paris: CNRS Editions.

Bourdieu, P. (1987). Programme pour une sociologie du sport. En : Bourdieu, Pierre. Choses dites. (pp. 203-216). Paris: Minuit.

Bracht, V. (1997). Sociologia crítica do esporte: uma introdução. Vitória: Centro de Educacao Fisica e Desportos UFES.

Brohm, J. M. (1975). Corps et politique. Paris: J.-P. Delarge.

Brohm, J.M. (1976). Sociologie politique du sport. Paris: Éd. Jean-Pierre Delarge.

Cancella, K. B. y Santos, L. M. (2012). Para o desenvolvimento physico do pessoal da Armada, institucionaliza-se o esporte: análises sobre as primeiras aproximações da Marinha do Brasil com as práticas esportivas e o processo de fundação da Liga de Sports da Marinha. Navigator, 8, 101-114. Recuperado de https://portaldeperiodicos.marinha.mil.br/index.php/navigator/article/view/ $\underline{458}$

Castellani Filho, L. (1988). Educação Física no Brasil: a história que não se conta. São Paulo: Papirus Editora.

Cavalcanti, K. B (1984). Esporte para todos: um discurso ideológico. São Paulo: IBRASA.

Chartier, R. y Vigarello, G (1982). Les trajectoires du sport. Le débat, 19, 35-58. Recuperado de https://www.cairn.info/revue-le-debat-1982-2-page-35.htm\#

Corrêa, J. N. (2017). Sports na terra dos rincões: Acre -1909 a 1922. Revista Brasileira de Estudos do Lazer, 1(3), 24-45. Recuperado de https://periodicos.ufmg.br/index.php/rbel/article/view/583/398 


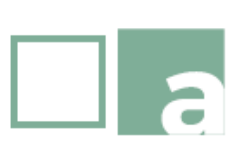

\section{Similitudes y diferencias en la historiografia del deporte en Brasil y Francia: un diálogo con "Histoire du sport" de Thierry Terret}

Dacosta, L. P. (1971). Diagnóstico da Educação Física/Desportos no Brasil. Rio de Janeiro: Ministério da Educação e Cultura, Fundação Nacional de Material Escolar.

Dacosta, L. P. (2016). E depois da década dos megaeventos. Rede Nacional de Treinamento. Brasilia: Ministerio do Esporte.

Dalben, A (2011). Inezil Penna Marinho: formação de um intelectual da educação física. Movimento, 17(1), 59-76. Recuperado de https://seer.ufrgs.br/Movimento/article/view/16968

Defrance, J. (2012). Sociologie du sport. Paris: La Découverte.

Dias, C. A. (2010). A sociologia figuracional e os estudos do esporte. Revista Brasileira de Ciências do Esporte, 31(2), 155-169. Recuperado de http://revista.cbce.org.br/index.php/RBCE/article/view/524

Dias, C. A. (2018). Esportes nos confins da civilização: Goiás e Mato Grosso. 1866-1936. Rio de Janeiro: 7 Letras.

Dias, D. C. y Soares, C. L. (2014). Entre velas, barcos e braçadas: Belém no reflexo das águas (do final do século XIX à década de 1920). Projeto História, 49, 165-196. Recuperado de https://revistas.pucsp.br/revph/article/view/19712

Diestchy, P, Gastaud, y Mourlane, S. (2006). Historie politique des coupes du monde de football. Paris: Vuibert.

Drumond, M. (2014). Estado novo e esporte: a política e o esporte em Getúlio Vargas e Oliveira Salazar (1930-1945). Rio de Janeiro: 7Letras.

Dunning, E. (1999). Sport matters: Sociological studies of sport, violence, and civilization. London: Routledge.

Duret, P. (2019) Sociologie du sport. Paris: Presses Universitaires de France.

Furtado, H. L., Quitzau, E. A. y Moraes e Silva, M. (2018). Blumenau e seus imigrantes: apontamentos acerca da emergência de uma cultura física (18501899). Movimento, 24(2), 665-676. Recuperado de https://seer.ufrgs.br/Movimento/article/view/81849

Góis Junior, E., Lovisolo, H. R. y Nista-Piccolo, V. L. (2013). Processo Civilizador: apontamentos metodológicos na historiografia da Educação Física. Revista Brasileira de Ciências do Esporte, 35(3), 773-783. Recuperado de https://www.scielo.br/scielo.php?script=sci_arttext\&pid=S0101$\underline{32892013000300017}$ 
Ghiraldelli Jùnior, P. (1988). Educação física progressista. São Paulo: Edições Loyola.

Guttmann, A. (1978). From ritual to record: The nature of modern sports. New York: Columbia University Press.

Guttmann, A. (2002). The olympics, a history of the modern games. 2nd ed. Urbana, IL: University of Illinois Press.

Guttmann, A. (2004). Visando a modernidade arco e flecha e a modernização do Japão. Movimento, 10(3), 9-21. Recuperado de https://seer.ufrgs.br/Movimento/article/viewFile/2847/1459

Guttmann, A. (2006). Du rituel au Record, la nature des sports modernes. Paris: L'Harmattan.

Guttmann, A. (2019). Del ritual al récord. In: P. A. Scharagrodsky y C. R. Torres. El rostro cambiante del deporte. Perspectivas historiográficas angloparlantes, 1710-2010 (pp. 19-66). Buenos Aires: Prometeo Libros.

Holt, R (1989). Sport and the British: a modern history. London: Oxford University Press.

Horta, J. S. B. (1994). O hino, o sermão e a ordem do dia: regime autoritário e a educação no Brasil, 1930-1945. Rio de Janeiro: Editora UFRJ.

Krüger, M. (2015) Global Perspectives on Sports and Movement Cultures: From Past to Present - Modern Sports between Nationalism, Internationalism, and Cultural Imperialism. The International Journal of the History of Sport, 32:4, 518$534 . \quad$ Recuperado de: https://www.tandfonline.com/doi/abs/10.1080/09523367.2015.1017473

Linhales, M. A. (2009). A escola e o esporte: uma história de práticas culturais. São Paulo: Cortez Editora.

Loudcher, J.F. (2008). À propos de la traduction française du livre de Allen Guttmann, From Ritual to Record: the Nature of Modern Sports. Staps, (2), 3951. Recuperado de https://www.cairn.info/revue-staps-2008-2-page-39.htm

Loudcher, J. F. (2020). Processo civilizador e transformações sociais: uma análise das teorias elisianas em relação às ciências sociais do esporte. História Questões e Debates, 68(2), 1-23.

Lucena, R. F. (2001). O Esporte na Cidade. Campinas: Autores Associados. 


\section{Similitudes y diferencias en la historiografia del deporte en Brasil y Francia: un diálogo con "Histoire du sport" de Thierry Terret}

Lucena, R. F (2010). Esporte, cidade e modernidade: Recife. In: V. A. de Melo. (Org.). Os sports e as cidades brasileiras: transição dos séculos XIX e XX (pp. 265-283). Rio de Janeiro: Apicuri.

Medeiros, C. C. C. y Godoy, L. (2009). As referências de Pierre Bourdieu e Norbert Elias na Revista Brasileira de Ciências do Esporte: mapeando tendências de apropriação e de produção de conhecimento na área da Educação Física (1979-2007). Revista Brasileira de Ciências do Esporte, 30(2), 199-214. Recuperado de http://revista.cbce.org.br/index.php/RBCE/article/view/445

Melo V. A. (1999). História da educação física e do esporte no Brasil: panorama e perspectivas. São Paulo: Ibrasa.

Melo V. A. (2001). Cidade Sportiva: primórdios do esporte no Rio de Janeiro. 1. ed. Rio de Janeiro: Relume Dumará.

Mezzadri, F. M. et al (2015). Sport policies in Brazil. International Journal of Sport policy and politics, 7(4), 655-666. Recuperado de https://www.tandfonline.com/doi/pdf/10.1080/19406940.2014.937737

Montenegro, N. R. y Soares, C. L. (2019). Cultura physica e vida ao ar livre: a reinvenção do litoral de Fortaleza (1920-1940). Movimento, 25, 25092. Recuperado de https://seer.ufrgs.br/Movimento/article/view/88925

Moraes e Silva, M. (2011). Novos modos de olhar outras maneiras de se comportar: a emergência do dispositivo esportivo da cidade de Curitiba (18991918). 2011. 227p. Tese (Doutorado) - Faculdade de Educação, Universidade Estadual de Campinas, SP.

Moraes e Silva, M. (2015). Comportamentos urbanos e esportes: contribuições para a esportivização do turf e da pelota basca em Curitiba (1899-1905). Licere, 18(3), 86-115. Recuperado de https://periodicos.ufmg.br/index.php/licere/article/view/1130

Moraes e Silva, M y Quitzau, E. A. (2018). A cultura física na cidade de Curitiba: a emergência de uma pedagogia corporal (1899-1909). Revista de Ciencias Sociales, 27(41), 275-296. Recuperado de http://www.revistacienciasociales.cl/ojs/index.php/publicacion/article/view/ $\underline{130}$

Moraes e Silva, M., Quitzau, E. A. y Soares, C. L. (2018). Práticas educativas e de divertimento junto à natureza: a cultura física em Curitiba (18861914). Educação e Pesquisa, 44, e178293. Recuperado de http://www.scielo.br/scielo.php?script=sci_arttext\&pid=S151797022018000100495\&lng=pt\&nrm=iso 
Moraes e Silva, M. y Loudcher, J.F. (2020). Jogos Olímpicos no Brasil e o governo federal brasileiro: dilemas entre o ter ou o ser. Espacio abierto: cuaderno venezolano de sociologia, 29 (2), 53-72. Recuperado de https://produccioncientificaluz.org/index.php/espacio/article/view/33053

Navarro, R. (2020). A politica de Esporte para Todos no Brasil: do governo militar ao advento da Nova República (1967-1988). Tese de Doutorado em Educação Física, Universidade Federal do Paraná, Curitiba, Brasil.

Navarro, R., Mezzadri, F. M. y Moraes e Silva, M. (2020). The genesis of the sport for all campaign in Brazil as seen through the Jornal dos Sports in the 1970s. Sport in Society, 1-16. Recuperado de https://www.tandfonline.com/doi/abs/10.1080/17430437.2020.1768241

Oliveira, A. S. F. et al (2015). Inezil Penna Marinho: Operações historiográficas na educação física (1940-1958). Movimento, 21(2), 291-302. Recuperado de https://seer.ufrgs.br/Movimento/article/view/46354

Parada, M (2009). Educando corpos e criando a nação: cerimônias civicas e práticas disciplinares no Estado Novo. Rio de Janeiro: Apicuri.

Pires, R. G., Dias, C. A. y Leite, M. C. M. (2014). História e memória do esporte em Jequié. Recorde: Revista de História do Esporte, 7 (1). Recuperado de https://revistas.ufrj.br/index.php/Recorde/article/view/1240

Pociello, C. (1981). Sports et société: approche socio-culturelle des pratiques. Paris, Vigot.

Quitzau, E. A. y Soares, C. L. (2010). "A força da juventude garante o futuro de um povo": a educação do corpo no sport Club Germania (18991938). Movimento, 16(3),89-108. Recuperado de https://seer.ufrgs.br/Movimento/article/view/10554

Quitzau, E. A. (2019). Entre a ginástica e o esporte: educação do corpo e manutenção da identidade nas sociedades ginásticas teutobrasileiras. Educação em Revista, 35, e217174. Recuperado de https://www.scielo.br/scielo.php?pid=S0102-

$46982019000100807 \%$ script $=$ sci_arttext

Quitzau, E. A. y Moraes e Silva, M. (2020). Educación Física y ciencia: una mirada historiográfica. The Journal of the Latin American Socio-cultural Studies of Sport, 12(1), 23-42. Recuperado de https://revistas.ufpr.br/alesde/article/view/71916 


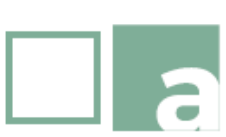

\section{Similitudes y diferencias en la historiografia del deporte en Brasil y Francia: un diálogo con "Histoire du sport" de Thierry Terret}

Reis, H. H. B. (2014). As contribuições de Eric Dunning para o desenvolvimento da sociologia do esporte no Brasil: uma introdução à sociologia figuracional. In: Dunning, E. Sociologia do esporte e processos civilizatórios. São Paulo: Annablume, 7-13.

Rocha Junior, C. P. y Espírito Santo, F. R. (2011). Futebol em Salvador: o início de uma história (1899-1920). Movimento, 17(3), 79-95. Recuperado de https://seer.ufrgs.br/Movimento/article/view/17683

Sarmento, C. E. (2013). A construção da nação canarinho: uma história institucional da seleção brasileira de futebol, 1914-1970. Rio de Janeiro: FGV Editora.

Silva, C. F. y Mazo, J. Z. (2017). Vestígios das Práticas Náuticas no Rio Grande do Sul. Licere, 20(2), 1-27. Recuperado de https://periodicos.ufmg.br/index.php/licere/article/view/1644.

Silva, C. F, Mazo, J. Z. y Tavares, O. (2018). O estabelecimento dos esportes náuticos no Rio Grande do Sul na primeira década do século XX: entre o ruder e o remo. Revista Brasileira de Ciências do Esporte, 4O(1), 24-31. Recuperado de https://www.scielo.br/scielo.php?pid=S0101$\underline{32892018000100024 \% \text { script }=\text { sci_arttext }}$

Souza, D. A. (2008). O Brasil entra em campo!: construções e reconstruções da identidade nacional (1930-1947). São Paulo: Annablume Editora.

Souza, E. S. (2017). Sport Club Amazonense: o divertimento em Manaus, 18971902. Revista Brasileira de Estudos do Lazer, 1(3), 5-23. Recuperado de https://periodicos.ufmg.br/index.php/rbel/article/view/582

Souza, J. y Marchi Júnior, W. (2010). Por uma gênese do campo da sociologia do esporte: cenários e perspectivas. Movimento, 16(2), 45-70. Recuperado de https://seer.ufrgs.br/Movimento/article/view/11159

Souza, J. y Marchi Júnior, W. (2011). Por uma sociologia da produção científica no campo acadêmico da Educação Física no Brasil. Motriz, 17(2), 349-360. Recuperado de https://www.scielo.br/scielo.php?pid=S1980$\underline{65742011000200014 \& \text { script }=\text { sci_abstract\&tlng }=p t}$

Souza, J., Starepravo, F. A. y Marchi Júnior, W. (2014). A sociologia configuracional de Norbert Elias-potencialidades e contribuições para o estudo do esporte. Revista Brasileira de Ciências do Esporte, 36(2), 429-445. Recuperado de https://www.scielo.br/scielo.php?pid=S0101$\underline{32892014000200429 \& \text { script }=\text { sci_abstract\&tlng }=\text { pt }}$ 
Souza, J., Oliveira, V. M. y Marchi Júnior, W. (2018). A "família intelectual" marxista e os estudos sociais do esporte no Brasil-recepção, rotinização e implicações epistemológicas. Revista Brasileira de Ciência e Movimento, 26(2), 103-112.

https://portalrevistas.ucb.br/index.php/RBCM/article/view/8545

Taborda de Oliveira, M. A. (2002). Educação Física escolar e ditadura militar no Brasil (1968-1984): história e historiografia. Educação e Pesquisa, 28(1), 51-75. Recuperado de https://www.scielo.br/scielo.php?script=sci_abstract\&pid=S151797022002000100004\&lng=es\&nrm=iso\&tlng=pt

Taborda de Oliveira, M. A. (2007). Renovação historiográfica na educação física brasileira. In: C. L. Soares, Pesquisas sobre o corpo: ciências humanas e educação (pp. 35-38). Campinas: Autores Associados.

Terret, T. (2008). Les Paris des Jeux olympiques de 1924. Biarritz: Atlantica.

Terret, T. (2019). Histoire du Sport. Paris: Presses Universitaires Françaises.

Terret, T. y Froissart, T. (2013). Le sport, l'historien et l'histoire. Reims : Éditions et Presses Universitaires de Reims.

Torri, D. y Vaz, A. F. (2006). Do centro à periferia. Sobre a presença da teoria crítica do esporte no Brasil. Revista Brasileira de Ciências do Esporte, 28(1), 185-200.

http://revista.cbce.org.br/index.php/RBCE/article/view/46

Vivier, C. y Loudcher, J. F. (2015). L'histoire de l'histoire du sport et de I'education physique en France, dix ans après... Sport History Review, 46(1), 10$17 . \quad$ Recuperado de https://journals.humankinetics.com/view/journals/shr/46/1/articlep18.xml

Vivier, C.; Loudcher, J. F. y Vieille-Marchiset, G. (2005). Histoire de l'histoire du sport et de l'éducation physique en France. Sport History Review, 36(1), 154178.

https://journals.humankinetics.com/view/journals/shr/36/2/articlep154.xml

Watson, R. y Gastaldo, E. L. (2019). Obituário: Eric Dunning, um pai fundador entre nós. Horizontes Antropológicos, 25(55), 339-345. Recuperado de: 
https://www.scielo.br/scielo.php?script=sci_arttext\&pid=S0104$\underline{71832019000300339}$

Recibido: 18 de Agosto de 2020

Aceptado: 9 de Octubre de 2020

Versión Final: 24 de Noviembre de 2020 